\title{
Maria Aparecida Lino Pauliukonis entrevista Patrick Charaudeau
}

O entrevistado neste número da Revista MATRAGA, Patrick Charaudeau, é ideólogo da Teoria Semiolinguística do Discurso e atualmente é professor emérito da Universidade de Paris Nord (Paris 13) e pesquisador do CNRS (Centre National de Recherche Scientifique). Mantém convênios de pesquisa com Universidades em vários países e no Brasil destacam-se suas parcerias com Universidades do Rio de Janeiro, de Minas Gerais, de São Paulo e do Rio Grande do Sul. Charaudeau possui vasta produção científica em livros e artigos publicados em importantes periódicos e que podem ser consultados em seu site pessoal (https:// www. patrickcharaudeau.com). O pesquisador tem mantido contato com vários centros de pesquisa brasileiros, por meio de publicações conjuntas, participação em eventos científicos, palestras e cursos como professor visitante entre outras atividades. Dentre esses convênios, destaca-se a parceria, por mais de 25 anos, com o CIADRIO, Centro Integrado de pesquisa que reúne pesquisadores das principais Universidades do Rio de Janeiro (UFRJ, UERJ, UFF e UNIRIO).

É com muito prazer que apresento esta "conversa" com o pesquisador e agradeço efusivamente à Revista Matraga a oportunidade de apresentar a um grande número de leitores os princípios de sua Teoria Semiolinguística e sua aplicabilidade aos estudos do texto e do discurso.

Maria Aparecida Lino Pauliukonis (UFRJ) 
Revista Matraga - Prezado Prof. Patrick Charaudeau, em sua Teoria Semiolinguística do Discurso, defende que a construção dos significados, em vários sistemas semiológicos, se faz por uma relação forma/sentido, que tem a língua como matéria prima e pela ação intencional de sujeitos (instâncias subjetivas), em um duplo processo de semiotização do mundo. Em que ela se distancia ou inova em relação a outras teorias sobre o discurso?

Patrick Charaudeau : Il y a plus de points communs que de différences avec les autres théories, ce qui est normal parce qu'il y a un fond épistémologique commun avec les autres approches de l'analyse du discours, de la sémiotique et de la sémiologie.

Cependant, du fait de mon point de vue interdisciplinaire, au Carrefour de plusieurs disciplines (sociologie, psychosociologie, information et communication, philosophie politique), j'ai introduit une dimension plus communicationnelle/interationelle qui n'existe pas dans d'autres approches.

Trad. ${ }^{1}$ : Há mais pontos em comum que diferenças com as outras teorias, o que é normal, pois há um fundo epistemiológico comum com as outras abordagens da análise do discurso, da semiótica e da semiologia.

Todavia, a partir de meu ponto de vista interdisciplinar, no cruzamento de diversas disciplinas (sociologia, psicossociologia, informação e comunicação, filosofia política), eu introduzi uma dimensão mais comunicacional /interacional que não existe em outras abordagens.

Revista Matraga - Sua teoria opera tanto com o linguístico quanto com o situacional e suas temáticas principais abrangem o tratamento do ato de linguagem, as operações linguísticodiscursivas a serviço da construção de imagens dos interagentes, o contrato de comunicação e a "mise-en-scène" dos dispositivos, na construção dos vários gêneros discursivos e dos modos de organização do discurso. De todas essas temáticas, de quais tem se servido mais em suas análises de textos mais recentes?

\footnotetext{
${ }^{1}$ A tradução de todas as respostas foi realizada pela entrevistadora.
} 
Patrick Charaudeau : Ce sont tous ces aspects, pris ensemble, qui caractérisent mon approche du discours : des actes de langage en situation, sous la responsabilité des acteurs de la communication, en situation d'échange interactionnel, procédant à des mises en scène du langage, en suivant certaines stratégies. Ce sont toutes ces notions que je mobilise dans mes analyses, mais toujours dans une démarche interdisciplinaire lors des interprétations.

Trad.: São todos esses aspetos, tomados em conjunto, que caracterizam minha abordagem do discurso: os atos de linguagem em situação, sob a responsabilidade dos atores da comunicação, em uma situação de troca interacional, procedentes das encenações da linguagem, a partir de certas estratégias. Essas são as noções que eu mobilizo em minhas análises, mas sempre com uma marca interdisciplinar no momento das interpretações.

Revista Matraga - O CIAD-Rio, que congrega grupo de pesquisadores da UFRJ, da UERJ, da UFF e da UNIRIO, tem mantido convênio e intercâmbio com você e sua teoria há muitos anos - completamos recentemente 25 anos de existência, com o Encontro de Semiolinguística, realizado pelas Universidades do Rio e de Niterói, em 2018. Como você avalia as consequências da aplicação de sua teoria em terras cariocas e fluminenses?

Patrick Charaudeau : Depuis nos premiers contacts, annés 1990 et autres qui doivent remonter aux années 2000, j'ai vu évoluer les travaux des étudiants et des plusiers collègues chercheurs qui ont produit beaucoup d'études qui toutes sont très intéressantes parce qu'ils appliquent ces notions à des analyses de la réalité brésilienn et je suis très heureux pour cette raison.

Trad.: Após nossos primeiros contatos, na década de 1990, e em outros que devem remontar aos anos 2000, eu tenho visto e avaliado trabalhos de estudantes e de vários colegas pesquisadores que têm produzido muitos estudos que são todos muito interessantes, porque procuram aplicar essas noções à análise da realidade brasileira e estou muito feliz por esta razão. 
Revista Matraga - Os princípios da Semiolinguística têm sido muito úteis nas nossas pesquisas, pois um dos objetivos dos pesquisadores do CIAD-RIO é viabilizar projetos que visem à formação integral do aluno como cidadão, como leitor crítico e produtor proficiente de textos, em diversas situações de interação social. Infelizmente, no Brasil, a Escola de nível fundamental e médio ainda continua com problemas de proficiência em leitura e em produção de textos, segundo avaliações internacionais. Você teria alguma sugestão metodológica para a melhoria do ensino de leitura e produção textual nesses níveis de ensino?

Patrick Charaudeau : Je ne connais pas suffisamment la situation de l'enseignement scolaire au Brésil pour pouvoir faire des suggestions. Mais je fais toujours une différence entre le "savoir savant" et le "savoir appliqué". Un enseignant, quel que soit le niveau auquel il enseigne, doit savoir traduire, transformer, son savoir théorique en savoir appliqué, mis à la portée des élèves. De cette façon, il peut trouver des solutions pratiques aux problèmes qui se posent à lui, lors de l'acte d'enseignement.

Trad.: Eu não conheço suficientemente a situação do ensino escolar no Brasil para poder fazer sugestões. Mas eu faço sempre uma diferença entre o «saber erudito » e o «saber aplicado ». Um ensino, qualquer que seja o nível, deve saber traduzir, transformar seu saber teórico em saber aplicado, na colocação feita aos alunos. Desta forma, é preciso encontrar soluções práticas para os problemas que se colocam durante o ato de ensinar.

Revista Matraga - Gostaria que falasse um pouco da importância de sua teoria dos sujeitos para a análise da performance de enunciadores perante destinatários /interpretantes e como o exame de estratégias diversas de restrição e de manipulação nas interações tem sido produtivo para os estudos do discurso.

Patrick Charaudeau : Finalement, dans ma théorie, tout repose sur l'existence d'un sujet parlant qui, surdéterminé en partie par un conditionnement social, essaie de s'individuer. Il s'agit donc d'un sujet parlant responsable, contrairement à certaines autres 
théories qui effacent ce sujet au profit d'un sujet social surdéterminant. L'individu est à la fois un être social et un être singulier. L'autre caractéristique de ce positionnement est le fait que ce sujet se dédouble en un sujet-personne et un sujet-énonciateur, de même que le récepteur de tout acte de langage se dédouble entre un sujet destinataire imaginé par le sujet-personne-locuteur, et un sujetpersonne-interprétant. Ainsi tout acte de langage est, du point de vue du sens, un acte de "co-construction".

Trad.: Finalmente, em minha teoria, tudo se relaciona à existência de um sujeito falante que, sobredeterminado em parte por um condicionamento social, tenta se individualizar. Trata-se de um sujeito falante responsável, contrariamente a certas outras teorias que apagam este sujeito favorecendo um sujeito social sobredeterminante. $\mathrm{O}$ indivíduo é ao mesmo tempo um ser social e um ser singular. Uma outra característica desse posicionamento é o fato de que esse sujeito se desdobra em um sujeito- pessoa e um sujeito-enunciador, do mesmo modo que o receptor de todo ato de linguagem também se desdobra entre um sujeito destinatário, imaginado pelo sujeito- pessoa-locutor, e um sujeito- pessoa interpretante. Assim, todo ato de linguagem e', do ponto de vista do sentido, um ato de « co-construção ».

Revista Matraga - A temática sobre "compreensão e interpretação", embora tratada, de forma geral, em vários de seus textos, mereceu dois estudos específicos: em 1995, quando publicou nos Anais do I Encontro franco-brasileiro de AD, na UFRJ, com o título de "Les conditions de compréhention du sens du discours" e mais recentemente, em 2017, sob o título de: "Compréhension et interprétation. Interrogations autour de deux modes d'appréhension du sens dans les sciences du langage". Gostaria que fizesse uma comparação entre as ideias dos dois textos e relatasse em que medida essa revisão acrescenta novos conceitos sobre o tema.

Patrick Charaudeau : Ces deux articles à plus vingt ans de distance sont complémentaires. Celui de 1995 met en place l'ensemble du processus de communication avec la définition des deux sujets de l'acte de langage, le "sujet communiquant" et le "sujet interprétant", l'interaction qui s'établit entre la notion de 
compréhension et interprétation, et les opérations auxquelles se livrent chacun de ces sujets. Il s'agit là de la description du mécanisme de construction du sens dans un processus d'interaction communicationnel. L'article de 2017 approfondit et détaille ce mécanisme. D'abord en précisant la différence entre "sens" et "signification" qui permet de distinguer "compréhension" et interprétation" à partir de l'herméneutique. Puis en envisageant les différentes opérations qu'est amené à faire le sujet interprétant, selon la position qu'il occupe dans les situations et contrats de communication, à travers le processus d'inférence.

Trad.: Esses dois artigos com mais de vinte anos de distanciamento são complementares. O de 1995 coloca como tema o conjunto do processo de comunicação com a definição dos dois sujeitos do ato de linguagem, o « sujeito comunicante » e o « sujeito interpretante ", a interação que se estabelece entre a noção de compreensão e interpretação, e as operações a que se entregam cada um desses sujeitos. Ele trata da descrição do mecanismo da construção do sentido em um processo de interação comunicacional. $\mathrm{O}$ artigo de 2017 aprofunda e detalha esse mecanismo. Aborda com precisão a diferença entre "sentido" e "significação", o que permite distinguir "compreensão e interpretação" a partir da hermenêutica. Depois objetiva focalizar as diferentes operações que realiza o sujeito interpretante, de acordo com a posição que ele ocupa nas situações e nos contratos de comunicação, por meio do processo de inferência.

Revista Matraga - $O$ ato de argumentação, visto como atividade linguística discursiva e situacional, ou como uma prática social, em determinada situação, é dotado de uma grande influência persuasiva. Como você vê o poder de influência das mídias sociais contemporâneas, que se utilizam da espetacularização e da presença frequente de "fake news"?

Patrick Charaudeau : Concernant la question de l'argumentation, je rappelle que je distingue "argumentation" et "persuasion", parce que le processus de persuasion est beaucoup plus ample que celui d'argumentation. La persuasion peut s'exercer à travers des discours qui ne sont pas argumentatifs en soi, mais parfois descriptifs ou narratifs, ou par divers procédés 
d'énonciation, ce qui apparaît dans mes écrits sur les discours politiques et propagandistes. Ce qui se passe dans les réseaux sociaux et dans les "fake news" ne relève pas nécessairement de l'argumentation. Le problème est plutôt celui du mensonge d'un côté, et de la crédulité de l'autre : - qu'est-ce qui fait que des gens croient en ce qui est dit, et comment les médias vont apporter du crédit, ou contester ce qui se dit.

Trad.: Concernente à questão da argumentação, eu relembro que distingo "argumentação e persuasão ", porque o processo da persuasão é mais amplo que o da argumentação. A persuasão pode ser exercida por meio de discursos que não são argumentativos em si mesmo, mas às vezes descritivos, narrativos ou por meio de diversos procedimentos enunciativos, o que aparece em meus escritos sobre os discursos políticos e propagandísticos. O que se passa nas redes sociais e nas "fake news" não depende necessariamente da argumentação. O problema reside mais numa mentira de um lado e numa crença do outro: - que é o que faz com que as pessoas creiam no que é dito, e como as "mídias" vão dar crédito ou contestar o que se diz.

Revista Matraga - Em relação à teoria dos "gêneros textual-discursivos" - fenômeno ligado ao contrato de restrições e de manobras -, você propõe o conceito de "visadas" que corresponde de forma geral a uma intencionalidade psico-sociodiscursiva que determina as expectativas ("enjeux") do ato de linguagem. Elas correspondem a atitudes enunciativas presentes em grande número de atos comunicativos e que se encontram além da ancoragem situacional. Em que sentido essa noção de "visadas" complementa ou acrescenta novos matizes à antiga noção de "estilo", que é retomada na proposta de Bakhtin?

Patrick Charaudeau : Si je propose de définir la notion de "genre discursif" à partir du contrat de communication, c'est pour apporter un point de vue différent sur cette notion qui est plus communicationnel. Cela permet de réintégrer les notions de genres premiers et seconds de Bakhtin, mais ce n'est pas pour moi une question de style qui renvoie davantage à une façon d'écrire et de parler de chaque locuteur, comme le dit Barthes. Tout cela est une question de terminologie, mais je tiens à changer le point de vue en 
entrant dans la question du genre par la situation de communication, et non pas par les caractéristiques discursives. Celles-ci sont le résultat de celle-là.

Trad.: Se eu proponho definir a noção de «gênero discursivo » a partir do contrato de comunicação, é para trazer um ponto de vista diferente sobre esta noção que tem base comunicacional. Isso permite reintegrar as noções de gêneros primários e secundários de Bakhtin, mas para mim não é uma questão de estilo a qual confere preferência a uma forma de escrever e de falar de cada locutor, como disse Barthes. Tudo isso é uma questão de terminologia, mas eu proponho trocar o ponto de vista ao tratar da questão do gênero pela de situação de comunicação e não pelas características discursivas. Estas são o resultado daquela.

Revista Matraga - Se é fato que o ato de comunicação significa em função da situação em que é produzido, da identidade e da intencionalidade dos interagentes, de seu propósito e das circunstâncias materiais de sua produção, a linguagem, sob essa perspectiva, deve ser vista como um instrumento que coloca os sujeitos em interação a fim de transformar um "mundo a significar" em um "mundo significado" discursivamente, como você propõe em sua teoria. Nesse sentido podemos concordar também com Wittgenstein que dizia que compreender uma língua é dominar uma práxis?

Patrick Charaudeau : C'est toute la différence avec le point de vue de Wittgenstein qui s'intéresse bien à la praxis, mais dont le modèle communicationnel n'est pas à proprement parler interactionnel dans un jeu avec les 4 sujets que, comme dejà dit, sont les sujets "communiquant", "énonçant", "destinataire" et "interprétant".

Trad.: Há toda uma diferença com o ponto de vista de Wittgenstein que se interessa pela praxis, mas em um modelo comunicacional e não propriamente em um falar interacional, em um jogo com os quatro sujeitos que são, como já foi dito, os sujeitos « comunicante », « enunciador », « destinatário » e « interpretante ».

Revista Matraga - No espaço enunciativo interacional, em sentido amplo, ganham relevância dois princípios básicos: o da 
alteridade - que realça o caráter dialógico da linguagem, e o da identidade - que aponta para a construção de identidades sociais e discursivas. Nesse sentido, você propõe que todo o processo interativo se assenta em um "cruzamento de olhares". Poderia acrescentar algo mais sobre esse conceito?

Patrick Charaudeau : La propose $d u$ process interative comme "le "cruzamento de olhares" est une métaphore pour expliquer le processus interactionnel avec ses 4 sujets que j'ai décrit précédemment.

Trad.: A proposta do processo interativo como «o cruzamento de olhares » é uma metáfora para explicar o processo interacional entre os 4 sujeitos que já descrevi anteriormente. 